Research article

\title{
Dyslipidemia among patients visiting tertiary care hospital
}

${ }^{1}$ KIST Medical College, Imadol, Lalitpur, Nepal

Singh $S^{1}$, Jha $B^{2}$

${ }^{2}$ Institute of Medicine, Maharajgunj, Kathmandu, Nepal

\section{ABSTRACT}

Background and objectives: The lipid profile is a group of tests that are often ordered together to determine risk of various diseases and is likely to be abnormal (dyslipidemia) in persons suffering from Coronary Heart diseases, Diabetes, Chronic Kidney Disease and Nephrotic Syndrome. This study attempts to compare a lipid profile in normal individuals and those suffering from above diseases visiting Institute of Medicine, Maharajgunj, Kathmandu, Nepal.

Material and Methods: Three hundred blood samples were collected from Inpatient and Outpatient Department. Out of which 94 blood samples of healthy individuals were assed as controls and 206 as test. The lipid profile tests were performed. All the data were analyzed using SPSS of 13 version, and the data were evaluated.

Results: Out of 206 test samples and 94 controls, 116 were dyslipidemic respectively. The prevalence of dyslipidemia were highest in subjects with Coronary Heart Disease (64\%) followed by Diabetes (50\%). Similarly the prevalence in Chronic Kidney Disease and Nephrotic Syndrome were $43.90 \%$ and $12.50 \%$ respectively.

Conclusion: Data clearly shows that there is a large variation in the lipid profile among normal and different diseased individuals. In Nepal, dyslipidemia may be more common in individuals suffering from Coronary Heart Disease, Diabetes and Chronic Kidney Disease.

Keywords: - Chronic Kidney Disease, Coronary Heart Disease, Diabetes, Dyslipidemia, Lipid Profile, Nephrotic Syndrome.

\section{INRODUCTION}

The lipid profile is a group of tests that are often ordered together to determine risk of Coronary Heart Diseases (CHD). The lipid profile includes total cholesterol (TC), high density lipoprotein cholesterol (HDL-C), low

Correspondence to:

Samir Singh, Lecturer and Incharge, Department of Clinical

Biochemistry,

KIST Medical College and Teaching Hospital

Imadol, Lalitpur, Nepal.

E-mail: samirbiochem 13@yahoo.co.in density lipoprotein cholesterol (LDL-C), and triglycerides (TG) $[1,2]$.

Dyslipidemia is a term used to describe lipid disordered metabolism. It encompasses change in blood lipid levels such as elevated serum LDL-C, raised TC, raised TG, and low level of HDL-C. It is broader term than 
hyperlipidemia, which refers to raised serum levels of one or more of TC, LDL-C, TG, or both TC and TG (combined hyperlipidemia), but does not include the low level of HDL-C [3].

The 2004 American Diabetes Association (ADA) treatment guidelines recommend that the following lipid criteria should be met for patients with diabetes: LDL-C $<2.6 \mathrm{mmol} / \mathrm{L}$ $(100 \mathrm{mg} / \mathrm{dl}), \mathrm{TG}<1.7 \mathrm{mmol} / \mathrm{L}(150 \mathrm{mg} / \mathrm{dl})$ for both gender and HDL-C $>1.0 \mathrm{mmol} / \mathrm{L}$ (40 $\mathrm{mg} / \mathrm{dl}$ ) in men and $1.3 \mathrm{mmol} / \mathrm{L} \mathrm{(50} \mathrm{mg/dl)} \mathrm{in}$ women [4]. The Third Adult Treatment Panel of the National Cholesterol Education Program (NCEP ATPIll) designated diabetes as a " Cardiovascular Disease (CVD) risk equivalent" for setting treatment goals for LDL-C [5]. The 2007 American Heart Association (AHA) recommend treatment of LDL-C to $<2.6 \mathrm{mmol} / \mathrm{L}$ [6].

The dominant dyslipidemia in diabetes is hypertriglyceridemia, which is most likely to be associated with hypercholesterolemia and with decreased HDL-C. [7, 8]. Elevated lipid levels also contribute to the development of CVD, including CHD, stroke, and coronary atherosclerosis. Dyslipidemia is probably the most widely known risk factor for atherosclerosis and CVD progression in the general population $[9,10]$.

It has also been reported that the patients with Chronic Kidney Disease (CKD) suffer from a secondary form of complex dyslipidemia [11]. The most important abnormalities are increase in serum TG levels and low HDL-C level. LDL-C particles are usually within normal range or slightly increased [12].

Dyslipidemia reveals a complex relationship to Nephrotic Syndrome (NS) as itself accelerates the progression of glomerular dysfunction along with cardiovascular damage [13]. A high plasma TC concentration is the most common abnormality found in it. Plasma TG may also be raised, especially in patients with heavy proteinuria. The magnitude of lipid abnormality correlates with the disease severity. In almost all NS patients, the number of circulating LDL-C particle is high; very low density lipoprotein cholesterol (VLDL-C) concentration are less likely to be raised [14].

Therefore dyslipidemia has been shown to be associated with diabetes, CHD and CKD [1418]. In Nepal in these aspects dearth literature has been published. The study has been carried out to observe the variation of lipid profile in those diseases in Nepalese context.

\section{Materials and Methods:}

Study design: This case-control study was conducted in Biochemistry Laboratory at Institute of Medicine, Maharajgunj, Kathmandu, Nepal from January 2008 to June 2008.

Sample: Three hundred blood samples were collected from Inpatient and Outpatient Department. Out of which 206 were test samples and 94 were controls. Samples of individuals suffering from Diabetes, CHD, CKD and NS were the test samples and those without above diseases were assed as controls. Majority of the individuals were in the age group ranging from 20-90 years.

Blood Collection: About $5 \mathrm{ml}$ overnight fasting (12-14 hours) venous blood sample were collected under aseptic condition from the study subjects. Blood serums were then isolated and were subjected to Lipid profile tests. 
Lipid profile tests: The TC, HDL-C, and TG were analyzed enzymatically, using the kits provided by Human diagnostics and the LDL$\mathrm{C}$ was calculated using Friedewald formula [19]. All the estimations were done using EVOLUTION 3000 semi-auto analyzer.

Statistical analysis: All the data were analyzed with the help of the computer software SPSS (Statistics Package for Social Sciences) of 13 version, and the data were evaluated.

\section{Results:}

Figure 1 presents the age and sex distribution for Males and Females. Overall male and female participants were $60 \%$ and $40 \%$ respectively. Most of the subjects belong to age group 40-60 years i.e. 52.66\%. The age group below 40 and above 60 years was $24 \%$ and $22.66 \%$ respectively.

Figure 1: Demographic details of participants according to Age and Sex.

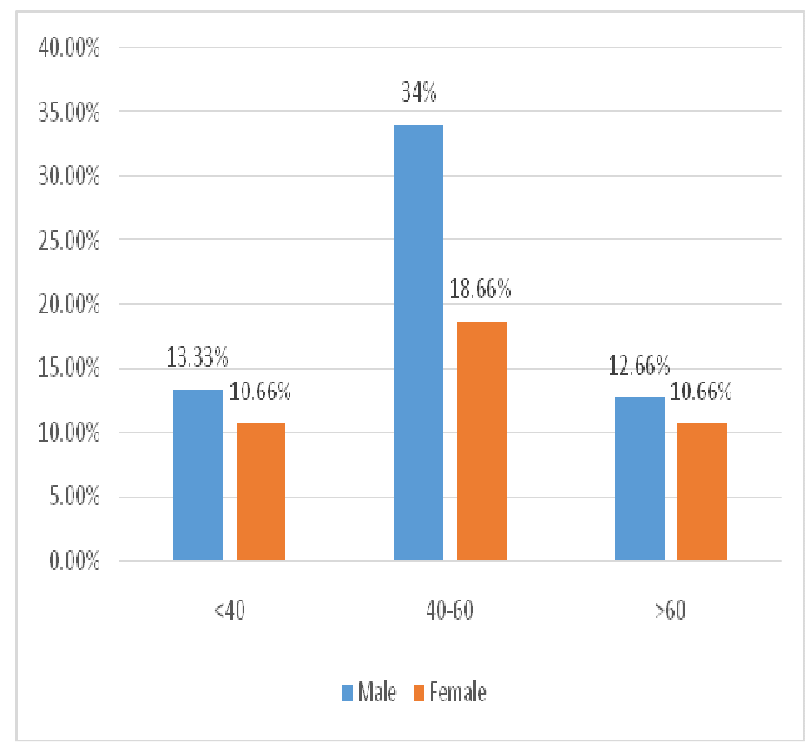

The data of the Table 1 shows the overall prevalence of Dyslipidemia in subjects with Diabetes, CHD, CKD and NS were 50\%, $64.28 \%, 43.90 \%$ and $12.5 \%$ respectively.
Of the subjects with Diabetes, CHD and CKD, a dyslipidemia was statistically significant $(p<0.05)$ and was no significant in NS when compared to the healthy subjects.

The prevalence of dyslipidemia on sex of the subjects having Diabetes, CHD, CKD and NS showed that the females were less affected as compared to males .

Table 1: Comparison of dyslipidemia in control and test groups

\begin{tabular}{|c|c|c|c|c|c|}
\hline & $\begin{array}{l}\text { Control } \\
(94)\end{array}$ & $\begin{array}{l}\text { DM } \\
(52)\end{array}$ & $\begin{array}{l}\text { CHD } \\
(56)\end{array}$ & $\begin{array}{l}\text { CRD } \\
(82)\end{array}$ & $\begin{array}{l}\text { NS } \\
(6)\end{array}$ \\
\hline $\begin{array}{l}\text { Dyslipid } \\
\text { emia }\end{array}$ & $\begin{array}{l}16 \\
(17 \%)\end{array}$ & $\begin{array}{l}26 \\
(50 \%)\end{array}$ & $\begin{array}{l}36 \\
(64.28 \%)\end{array}$ & $\begin{array}{l}36 \\
(43.90 \%)\end{array}$ & $\begin{array}{l}2 \\
(12.50 \%)\end{array}$ \\
\hline Normal & $\begin{array}{l}78 \\
(83 \%)\end{array}$ & $\begin{array}{l}26 \\
(50 \%)\end{array}$ & $\begin{array}{l}20 \\
(35.72 \%)\end{array}$ & $\begin{array}{l}46 \\
(56.10 \%)\end{array}$ & $\begin{array}{l}14 \\
(87.50 \%)\end{array}$ \\
\hline$P$ value & & 0.003 & $<0.001$ & 0.006 & 1.0 \\
\hline
\end{tabular}

DM=Diabetes mellitus; CHD=Coronary Heart diseases; $\mathrm{CKD}=$ Chronic Kidney diseases and NS= Nephrotic Syndrome

\section{Discussion:}

This study is to assess prospectively the association between a large number of lipids and the subsequent decline in cardiac and renal function in the general population. In this study, 206 clinically documented diseased cases and 94 normal healthy controls showed that the TC, LDL-C, and TG levels were significantly higher while HDL-C was lower. Our data indicated that, of the subjects (total $=206$ ) with Diabetes, CHD, CKD and NS, 100 (48.54\%) subjects were detected dyslipidemic. Among 94 controls, 16 (17\%) were also found to be dyslipidemic. This findings was comparable to the study done by Ernesto L. Schiffrin et al [16]. 
The most common pattern of dyslipidemia in the patients with diabetes consists of elevated levels of TG and low levels of HDL-C [7, 17]. The data showed that there was significant association $(\mathrm{p}<0.05)$ between Diabetes and dyslipidemia. Moreover dyslipidemia is common among both male and female participants. Diabetes is designated as an independent cardiovascular diseases risk factor in the National Cholesterol Education Panel Audit Treatment Panel III report, and those investigators set a goal of an LDL-C concentration $<100 \mathrm{mg} / \mathrm{dL}$ for persons with diabetes [5]. It is well known that increased levels of LDL-C, TG and TC and decreased levels of HDL-C are also indicative of increased incidence of cardiac events and are considered as risk factors [9, 10]. In the subject group of CHD having abnormal lipid profile, some had elevated level of LDL-C and serum TG and also low level of HDL-C. Our data indicated that the dyslipidemia in CHD is statistically significant and its prevalence was more in male as compared to female participants.

The presence of dyslipidemia is associated with CKD in patients and likely contributes to the development of both renal disease and CHD [20]. Lipoprotein metabolism is a dynamic system that can be disturbed in CKD owing to alterations in apolipoproteins, lipid transfer proteins, lipolytic enzymes and lipoprotein receptors. When GFR falls below $60 \mathrm{~mL} / \mathrm{min}$ (CKD stage 3), there is a fall in the ratio of apolipoprotein $\mathrm{AI}$ (apoAI) to apolipoprotein CIII (apo CIII) in spite of normal cholesterol and triglyceride. As renal function deteriorates in non-nephrotic patients with CKD, triglyceride concentrations increase while HDL concentrations declines and there is accumulation of the more atherogenic, small dense low-density lipoprotein (LDL) particles
[21]. Our study also revealed that the subjects with CKD had elevated level of serum TG, LDL-C and low level of HDL-C. Data indicated the significant relation between dyslipidemia and CKD.

Finally in the group of subject having NS, dyslipidemia was found to be no significant. Even though it is insignificant, there must be association of dyslipidemia with it as dyslipidemia reveals a complex relationship to NS as itself accelerates the progression of glomerular dysfunction $[13,14]$. In summary, dyslipidemia has prospective influence on these diseases and it is one among the culprits.

\section{CONCLUSIONS}

Therefore our data clearly concludes that there is a large variation in the lipid profile among normal and those subjects having Diabetes mellitus, Coronary Heart Disease, Chronic Kidney Disease and Nephrotic syndrome. Dyslipidemia may be more common in them. The proportion of male and female participants with dyslipidemia are nearly same in diabetes and CKD group whereas in group of subjects with CHD, the proportion of male is five times greater than female participants.

\section{ACKNOWLEDGEMENT}

Authors wish to acknowledge the support of all the participants of the study.

\section{REFERENCES}

1. Godkar PB, Godkar DP. Textbook of Medical Laboratory Technology. 2nd ed. Mumbai (India): Bhalani Publishing House; 2008. P.371.

2. Medline Plus. Coronary risk profile. (Online). 2010 May23 ( Cited August 26, 2010); Available

from: 
URL:http://www.nim.nih.gov/medlineplus/en cy/article/003491.htm

3. Gross Z, Reese GE. Dyslipidaemia: the condition and non-drug management. Hospital Pharmacist. 2005;12:169-75.

4. American Diabetes Association. Dyslipidaemia management in adults with diabetes. Diabetes Care. 2004;27(1):68-71.

5. Expert Panel on Detection, Evaluation, and treatment of High Blood Cholesterol in Adults. Executive summary of the third repot of the National Cholesterol Education Program (NCEP) Expert Panel on Detection, Evaluation, and treatment of High Blood Cholesterol in Adults (Adult Treatment Panel lll). JAMA 2001; 285: 2486-97.

6. Buse JB, Ginsberg HN, Bakris GL, Clark NG, Costa F, Eckle R, et al. Primary prevention of cardiovascular diseases in people withdiabetes mellitus. Circulation.

7. Durrington PN. Diabetic dyslipidaemia. Baillier'sClinEndocrinolMetab. 2000;13: 26578.

8. Malmstrom R, Packard CJ, Caslake $\mathrm{M}$ et al. Defective regulation of triglyceride metabolism by insulin in the liver in noninsulin-dependent diabetes mellitus. Diabetologia. 1997; 40: 454-62.

9. Foley RN, Parfrey PS, Sarnak MJ. Clinical epidemiology of Cardiovascular disease in chronic renal disease. Am J Kidney Dis. 1998;32(3): 112-19

10. Chmielewski M, Carrero JJ, Nordfors L, Lindholm B, Peter Stenvinkel. Lipid disorders in chronic kidney disease: reverse epidemiology and therapeutic approach. J Nephrol. 2008; 21:635-44.

11. Wanner C, Quaschning T. Dyslipidemia and renal disease: pathogenesis and clinical consequences. CurrOpinNephrolHypertens. 2001;10(2): 195-01.

12. Piecha G, Adamczak M, Ritz E. Dyslipidemia in chronic kidney disease. Pol Arch Med Wewn. 2009; 119(8): 487-92.

13. Lechleitner M. Dyslipidaemia and Renal Disease. J Clin Basic Cardiol. 2000;3(1):3-6.

14. Majumdar A, Wheeler DC. Lipid abnormalities in renal disease. J R Soc Med. 2000; 93(4): 178-82.

15. Prichard SS. Impact of Dyslipidemia in EndStage Renal Disease. J Am SocNephrol. 2003;14:315-20.
16. Schiffrin EL, Lipman ML, Mann JFE. Chronic Kidney Disease: effects on the Carciovascular System. Circulation. 2007; 116:85-97.

17. Battisti WP, Plamisano BJ, Keane WF. Dyslipidaemia in patients with Type 2 Diabetes: Relationship between Lipids, Kidney Diseases and Cardiovascular Disease. ClinChem Lab Med. 2003;41: 1174-81.

18. Coulston AM. Cardiovascular disease risk in women with diabetes need attention. Am J ClinNutr. 2004;79(6):931-32.

19. Fridewald WT, Levy RI, Frederickson DS. Estimation of the concentration of low density lipoprotein cholesterol in plasma without use of the preparative ultra centrifuge. Clin Chem. 1972; 18: 499-02.

20. Marino A, Tannock LR. Role of dyslipidemia in patients with chronic kidney disease. Postgrad Med. 2013; 125(4): 28-37.

21. Chan DT, Irish AB, Dogra GK, Watts GF. Dyslipidaemia and cardiorenal disease: mechanisms, therapeutic opportunities and clinical trials. Atherosclerosis. 2008; 196(2): 823-34. 